\title{
Carcinoma of the Ovary Presenting as Cutaneous Metastases
}

\section{Monisha Venugopal, Naresh Duthaluri, Prabhu Purushothamanan, Anukiran Ravichandran, Arcot Rekha*}

Sri Ramachandra Medical College and Research Institute, Sri Ramachandra University, Chennai, India

Email: ^rekha_a@yahoo.com

How to cite this paper: Venugopal, M., Duthaluri, N., Purushothamanan, P., Ravichandran, A. and Rekha, A. (2016) Carcinoma of the Ovary Presenting as Cutaneous Metastases. Case Reports in Clinical Medicine, 5, 500-504.

http://dx.doi.org/10.4236/crcm.2016.511063

Received: June 24, 2016

Accepted: November 26, 2016

Published: November 29, 2016

Copyright $\odot 2016$ by authors and Scientific Research Publishing Inc. This work is licensed under the Creative Commons Attribution International License (CC BY 4.0).

http://creativecommons.org/licenses/by/4.0/

\section{(c) (i) Open Access}

\begin{abstract}
Introduction: Cutaneous metastasis is common from malignancies of the genitourinary system and occasionally from the digestive system. Cutaneous metastases, due to ovarian carcinoma as a presenting feature, being diagnosed on cytology, are uncommonly reported. Case Report: A 70-year-old lady presented with a cutaneous nodule and progressive abdominal distension. Investigations for metastatic nodule showed it to be a lesion from the ovary. Discussion: Carcinoma ovary is often diagnosed when patients present with ascites and the association with a parietal wall deposit is uncommon. The occurrence of a parietal wall nodule when the ascites is negative for malignant cells is not previously documented. Conclusion: We discuss literature of the malignancies that present with a parietal wall metastases and the management of ovarian carcinoma.
\end{abstract}

\section{Keywords}

Carcinoma Ovary, Cutaneous Nodule, Cytology

\section{Introduction}

Skin metastases occur in $0.6 \%-10.4 \%$ of all patients with cancer and represent $2 \%$ of all skin tumors. Women with skin metastases have the following distribution in decreasing order of frequency of primary malignancies: breast, ovary, oral cavity, lung, and large intestine. In men, the distribution is as follows: lung, large intestine, oral cavity, kidney, breast, oesophagus, pancreas, stomach, and liver. A wide morphologic spectrum of clinical appearances has been described in cutaneous metastases. This variable clinical morphology included nodules, papules, plaques, tumors, and ulcers. We present our patient who presented with ascites and a cutaneous nodule due to an ovarian malignancy. 


\section{Case Report}

A 70-year-old lady, presented with complaints of swelling on the left flank and abdominal distension that was progressive over 6 months. Examination revealed a $2 \times 2$ $\mathrm{cm}$ firm swelling on the left flank on the parietal wall. Patient had ascites and was dyspoenic. Investigations done showed a normal blood profile, upper and lower gastro intestinal endoscopy was normal. CT of the abdomen showed massive ascites with peritoneum, omental nodularity, and enlarged left lobe of an irregular coarse nodular liver and a thin rim of fluid with in endometrial cavity. Patient had bilateral minimal pleural effusion and spondylosis of L5 vertebra with L1 wedge compression fracture. Ascitic fluid was negative for malignancy and acid fast bacilli, ADA was $11.71 \mathrm{U} / \mathrm{L}, \mathrm{LDH}$ was $378 \mathrm{U} / \mathrm{L}$, and protein was $5.9 \mathrm{gms} / \mathrm{dl}$. A clinical gynaecological examination was normal. CA-125 was $2330.60 \mathrm{u} / \mathrm{ml}$ (N 0 - 35 units/ml). PET Scan done showed ill defined soft tissue density lesion in the parametrium —right adenexa abutting the anterior wall of the rectum and the uterus with right ovary could not be visualized and a nodular soft tissue density lesion in the left anterior lower abdominal wall (Figure 1). A FNAC from the parietal wall nodule was positive for metastatic carcinomatous deposit (Figure 2).

A diagnosis of carcinoma of the ovary-stage IV was made and patient was referred to the oncologist for chemotherapy with taxanes and cisplatinum. The patient condition

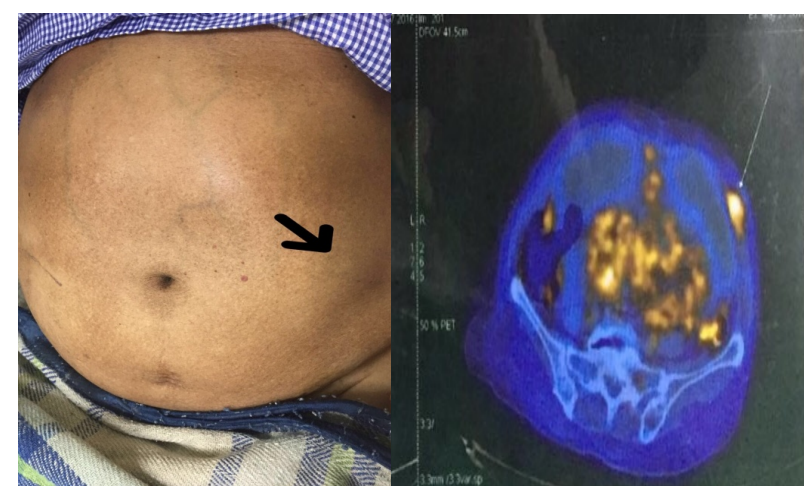

Figure 1. Shows the parietal wall nodule and the PET scan of the abdomen.

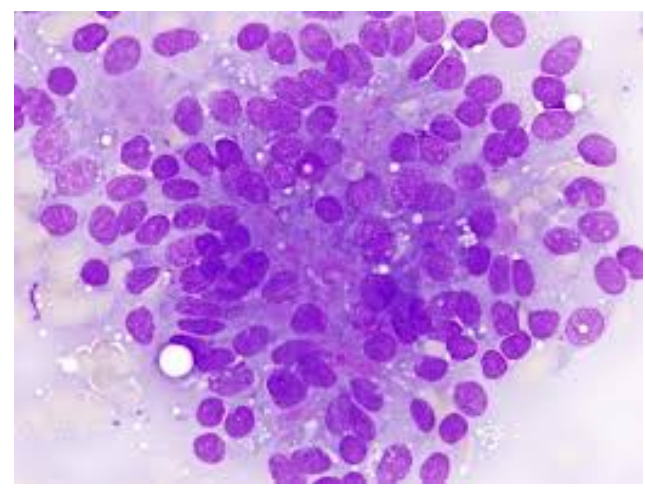

Figure 2. Cytology of the parietal wall nodule showing malignant cells. 
deteriorated in two weeks and was unable to withstand the suggested chemotherapy.

\section{Discussion}

Cutaneous metastasis from an ovarian tumor is a relatively unusual presentation in clinical practice. Distant metastatic deposit to skin is uncommon compared with organs such as liver, lungs, bones. Almost 9\% of internal cancers may have parietal metastasis and in about $0.5 \%-1 \%$ it is the presenting feature [1] [2].

Cutaneous metastases are often from the breast, lungs [3] [4] [5] [6], colon, stomach, upper aero digestive tract, uterus, and kidney. Most cases presenting as cutaneous nodule have peri umbilical nodule (Sister Mary Joseph's). Cutaneous metastases usually presents as solitary/multiple painless, firm to hard nodule, which may be skin colored or blue brown, reddish purple, morphia like sclerotic form [7] [8] [9] [10]. The most common sites affected are skin in vicinity of the affected organ, umblical (Sister Mary Joseph's nodule), recent operated site, laparoscopic port site, or previously tapped site. Cutaneous metastasis occurs as the result of lymphatic/hematogenous dissemination of tumor. Genitourinary primaries are known to metastasize to the parietal wall from kidney, bladder, prostate and testis. Metastasis to the skeletal muscle is however uncommon and it attributed to muscle movement and destruction by turbulence The dermatologist often see these patients and in the background of a known malignancy there is a need for a high index of suspicion as they account for only $1 \%$ of lesions. The relative frequency of skin metastasis correlates with the type of primary cancer, which occurs in each sex. For instance, lung and breast carcinomas are the most common primaries that send skin metastasis in men and women, respectively [11]. Patient with solitary cutaneous metastasis without other evidence of dissemination may have a better survival. Cutaneous disease is usually indicative of poor prognosis and is often a preterminal event

Ovarian carcinoma is the fifth most commonly diagnosed cancer among women in the world where whites are at higher risk compared to the black and Hispanic [12]. It occurs in $17 \%$ of Indian women. The overall survival rate is less than 50 years. High mortality in this carcinoma is because nearly $75 \%$ of women present with the advanced disease. Incidence of ovarian carcinoma among Indian women was 9.5/100,000 female in 2012. And there was a significant decrease from 2003 to 2012 was it was $12.5 / 10,000$ female, and the mortality had decreased from 9.1 - 8.1/10,000 female during the period of 2003-2012. A cohort study found a relation between diary consumers, red meat and processed meat consumers with ovarian carcinoma. BRCA 1 and 2 gene, obesity also contribute.

The symptoms of ovarian carcinoma are non specific like abdominal pain , bloating, altered bowel habits (with episodes of constipation and loose stools), nausea vomiting, abdominal distention, mass/swelling in the abdomen, loss of weight, loss of appetite, early satiety, back pain, menstrual irregularities in ovulating women, and post menopausal bleeding.

Patients present with locally advanced disease in pelvis, with contagious extension to 
the uterus, fallopian tubes, colon, rectum.Ovarian malignancies are often associated with ascitis and one third have pleural effusion. Parietal wall metastasis, enlarged and nodular liver and lymph nodal masses may also be the presentation.

Ultrasound is the initial investigation of choice and CA 125 is often elevated.Others tumour markers include CA19-9, CA 72-4, CA-15-3, fibroblast growth factor, hataglobin-alpha. Spiral CT is accurate in the detection of peritoneal metastasis from ovarian carcinoma although sensitivity is reduced in pt with tumor implant $1 \mathrm{~cm}$ or smaller [13].

Surgery is the initial treatment of choice for ovarian carcinoma, provided patients are medically fit. Chemotherapy can be given to the patient who are not fit for surgery and can be considered later for surgery [14]. The aim of the surgery is to confirm the diagnosis, define the extent of disease, and resect all visible tumors. The role of cytoreduction was demonstrated by Griffiths in 1975 and has been confirmed by many others. In most cases, surgery should be followed by chemotherapy with paclitacel, docetaxel and carboplatin. Gemcitabine and bevacizumab are also effective in platinum sensitive recurrence [15] [16]. Olaparib $400 \mathrm{mg}$ PO BID continuously may be used as monotherapy for advanced ovarian cancer with deleterious or suspected deleterious germ line $B R C A$ mutations (as detected by an FDA-approved test, BRACAnalysis CDxTM) in patients who have been treated with three or more prior lines of chemotherapy [17] [18]. Hormonal therapy with tamoxifen and letrozole may be considered for patients who have asymptomatic recurrence or who require a break from regular chemotherapy if they are not tolerating treatment well.Radiotherapy is not very useful in ovarian carcinoma.

\section{Conclusion}

Cutaneous metastases as a presenting feature of an internal malignancy are uncommon. Their diagnosis by cytology is useful in identifying obscure lesions that are not commonly encountered.

\section{References}

[1] Rafii, A., Ferron, G., Lacroix-Triki, M., Dalenc, F., Gladieff, L. and Querleu, D. (2006) Abdominal Wall Metastasis of Ovarian Carcinoma after Low Transverse Abdominal Incision: Report of Two Cases and Review of Literature. International Journal of Gynecological Cancer, 16, 334-337. https:/doi.org/10.1111/j.1525-1438.2006.00511.x

[2] Krathen, R.A., Orengo, I.F. and Rosen, T. (2003) Cutaneous Metastasis: A Meta-Analysis of Data. Southern Medical Journal, 96, 164-167. https:/doi.org/10.1097/01.SMJ.0000053676.73249.E5

[3] Mollet, T.W., Garcia, C.A. and Koester, G. (2009) Skin Metastases from Lung Cancer. Dermatology Online Journal, 15, 1.

[4] Udkoff, J. and Cohen, P.R. (2016) Adenocarcinoma of the Colon Presenting with Scrotal Metastasis: Case Report and Review of the Literature. Dermatology Online Journal, 22, pii: 13030/qt1jg0t4kw.

[5] Mueller, T.J., Wu, H., Greenberg, R.E., Hudes, G., Topham, N., Lessin, S.R., et al. (2004) Cutaneous Metastases from Genitourinary Malignancies. Urology, 63, 1021-1026.

https:/doi.org/10.1016/j.urology.2004.01.014 
[6] Kumar, M., Goel, M.M., Pahwa, H.S. and Kumar, A. (2012) Cytodiagnosis of Cutaneous Metastases from Gall Bladder Carcinoma on Scalp. Journal of Cytology, 29, 277-278. https:/doi.org/10.4103/0970-9371.103954

[7] Kumar, P.V., Salimi, B., Musallaye, A. and Tadayyon, A. (2000) Subcutaneous Metastasis from Transitional Cell Carcinoma of the Bladder Diagnosed by Fine Needle Aspiration Biopsy. A Case Report. Acta Cytologica, 44, 657-660. https:/doi.org/10.1159/000328543

[8] Salemis, N.S., Gakis, C., Zografidis, A. and Gourgiotis, S. (2011) Cutaneous Metastasis of Transitional Cell Bladder Carcinoma: A Rare Presentation and Literature Review. Journal of Cancer Research and Therapeutics, 7, 217-219.

[9] Akman, Y., Cam, K., Kavak, A. and Alper, M. (2003) Extensive Cutaneous Metastasis of Transitional Cell Carcinoma of the Bladder. International Journal of Urology, 10, 103-104. https:/doi.org/10.1046/j.1442-2042.2003.00571.x

[10] Kumar, S., Sharma, P.K. and Bera, M.K. (2015) Isolated Abdominal Wall Metastasis from Renal Cell Carcinoma: Unusual Presentation. Advanced Biomedical Research, 4, 65. https:/doi.org/10.4103/2277-9175.153883

[11] Hussein, M.R.A. (2010) Skin Metastasis a Pathologist's Perspective. Journal of Cutaneous Pathology, 37, e1-e20. https:/doi.org/10.1111/j.1600-0560.2009.01469.x

[12] Griffiths, C.T. (1975) Surgical Resection of Tumor Bulk in the Primary Treatment of Ovarian Carcinoma. Journal of the National Cancer Institute Monographs, 42, 101-104.

[13] Iyer, V.R. and Lee, S.I. (2010) MRI, CT, and PET/CT for Ovarian Cancer Detection and Adnexal Lesion Characterization. American Journal of Roentgenology, 194, 311-321. https:/doi.org/10.2214/AJR.09.3522

[14] Winter-Roach, B.A., Kitchener, H.C. and Dickinson, H.O. (2009) Adjuvant (Post-Surgery) Chemotherapy for Early Stage Epithelial Ovarian Cancer. Cochrane Database of Systematic Reviews, Jan 21, CD004706. https:/doi.org/10.1002/14651858.cd004706.pub3

[15] Pfisterer, J., Plante, M., Vergote, I., du Bois, A., Hirte, H. and Lacave, A.J. (2006) Gemcitabine plus Carboplatin Compared with Carboplatin in Patients with Platinum-Sensitive Recurrent Ovarian Cancer: An Intergroup Trial of the AGO-OVAR, the NCIC CTG, and the EORTC GCG. Journal of Clinical Oncology, 24, 4699-707.

https:/doi.org/10.1200/JCO.2006.06.0913

[16] Pujade-Lauraine, E., Hilpert, F., Weber, B., Reuss, A., Poveda, A., Kristensen, G., et al. (2014) Bevacizumab Combined with Chemotherapy for Platinum-Resistant Recurrent Ovarian Cancer: The AURELIA Open-Label Randomized Phase III Trial. Journal of Clinical Oncology, 32, 1302-1308. https:/doi.org/10.1200/JCO.2013.51.4489

[17] Ledermann, J., Harter, P., Gourley, C., Friedlander, M., Vergote, I., Rustin, G., et al. (2012) Olaparib Maintenance Therapy in Platinum-Sensitive Relapsed Ovarian Cancer. The New England Journal of Medicine, 366, 1382-1392. https:/doi.org/10.1056/NEJMoa1105535

[18] Yang, D., Khan, S., Sun, Y., et al. (2011) Association of BRCA1 and BRCA2 Mutations with Survival, Chemotherapy Sensitivity, and Gene Mutator Phenotype in Patients with Ovarian Cancer. JAMA, 306, 1557-1565. https:/doi.org/10.1001/jama.2011.1456 
Submit or recommend next manuscript to SCIRP and we will provide best service for you:

Accepting pre-submission inquiries through Email, Facebook, LinkedIn, Twitter, etc. A wide selection of journals (inclusive of 9 subjects, more than 200 journals)

Providing 24-hour high-quality service

User-friendly online submission system

Fair and swift peer-review system

Efficient typesetting and proofreading procedure

Display of the result of downloads and visits, as well as the number of cited articles

Maximum dissemination of your research work

Submit your manuscript at: http://papersubmission.scirp.org/

Or contact crcm@scirp.org 